\title{
ISCHAEMIC HEART DISEASE IN AFRICAN POPULATIONS
}

\author{
By J. F. Brock, D.M., F.R.C.P. \\ Professor of Medicine, University of Cape Town and Groote Schuur Hospital \\ and H. Gordon, M.D.(Cape Town)
}

Formerly Research Bursar, Clinical Nutrition Research Unit, Department of Medicine, University of Cape Town

Inter-racial epidemiology is a well-established procedure for investigating the aetiology of disease and for assessing the importance of environmental and genetic factors. The multi-racial population of the African continent has provided a fertile field for this sort of investigation; in particular, the inter-racial differences in the incidence of coronary heart disease have excited much interest and extensive studies are in progress to characterise these differences and the circumstances which have produced them. It is our purpose in this communication to review the data which are already available and tentatively to draw conclusions about their significance. A previous paper by one of us is brought up to date (Brock and Bronte-Stewart, 1955).

These populations are derived from several indigenous racial stocks plus European settlers in the last three hundred years. Hailey (1957) discusses the difficulties of defining the conventional stocks, but accepts the working classification into Bantu, Negroes, Hamites, Bushmen and Hottentots.

The Bushmen, a most primitive group, are very nearly extinct as a pure race; only a few thousands survive in the Kalahari desert and in South-West Africa. The Hottentots, who are probably a mixture of Bushmen and Hamitic elements, are similarly primitive and a numerically unimportant group. The Hottentot is, however, important in the genetic make-up of the Cape Coloured people (vide infra).

The true Negro has his home in West and West-Central Africa; the 'American Negro' is descended from this group. The rest of the true Negroes have been modified by admixture with the Eastern Hamites who apparently invaded Africa in successive waves from Asia (Seligman, 1957). One of the groups of Hamiticized Negroes, the Nilotes, are centred on the Nile valley, mainly in the Sudan, and apart from a small proportion living in Northern Uganda, they fall outside the

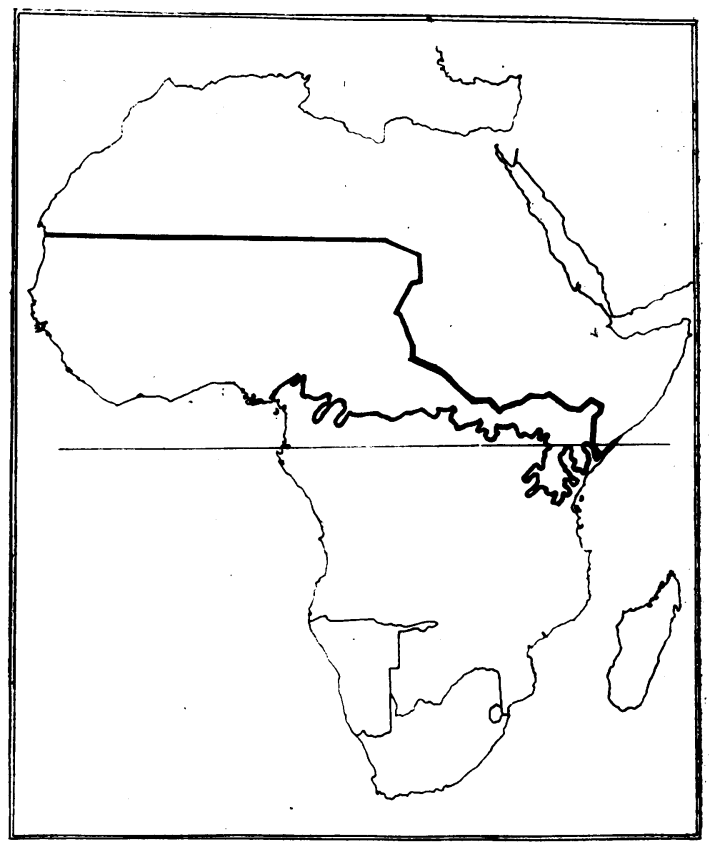

Fig. 1.-Map of Africa showing:

(I) Heavy line for W.H.O. region, 'Africa south of Sahara.'

(2) Wavy line-the Bantu line.

scope of this review. A second group, the NiloHamites, live in East and East-Central Africa (including Kenya and parts of Uganda and Tanganyika); the Masai, Nandi, Kipsigis and Suk are the well-known tribes of this group. The third and largest group are the Bantu-speaking $\mathrm{Ne}$ groids, or 'Bantu.' This group is derived from those Hamiticised Negroes who migrated southward from the equator. They came in contact with the Hottentots and Bushmen whom they displaced progressively southwards. Geographically, this group is mainly confined to the territory south of the 'Bantu-line' (Fig. I). They may be further divided into Eastern, Western and 
Southern Bantu (Seligman, 1957), and each of the sub-groups consists of a large number of tribal units, including Shona, Ndebele, Xhosa, Zulu, Swazi, Shangaan, Sotho (' Basuto '), Herero, etc., etc. The Bantu, of whom there are about 60 million (Hailey, 1957), are physically heterogeneous and their affinities are indicated mainly by linguistic traits and to a lesser extent by other cultural characteristics.

Mention must also be made of the Cape Coloured people, of whom there are about one million in the Union of South Africa, mainly centred on the Western Cape Province. When European settlement started from the Cape in I652 the Bantu were still 500 or more miles to the north and the south-western Cape Province of to-day was occupied by Hottentots and Bushmen. The latter were too primitive to survive the impact of European colonization; the Hottentots, however, were in part subdued, and as a result of miscegenation eventually merged with Indonesian and Malayan slaves who had been brought to the Cape Colony about 25 years later. Considerable mixture with the White race has occurred continuously, but it is only very recently that there has been any substantial mingling with the Bantu. Accordingly, they may be regarded as genetically distinct from the Bantu, while their cultural pattern is more of a European than an African type (Brock, 1949).

Finally, there are the permanent White populations who are of European origin and many of whom have lived in Africa for over 300 years. They are concentrated mainly in the Union of South Africa, with smaller numbers in Southern Rhodesia and the 'White Highlands' of Kenya. They are socially the 'privileged' people of Africa, and their mode of living does not differ significantly from that of people of Western European descent living elsewhere.

\section{Terminology}

'Coronary Heart Disease' is widely used to include atherosclerotic changes in the coronary arteries and the clinical syndromes which result from the effects of these arterial lesions on the myocardium.

'Ischaemic Heart Disease.' The W.H.O. Study group on Atherosclerosis and Ischaemic Heart Disease (1957) prefers the term ' ischaemic heart disease,' and it has been adopted in at least one text-book (Wood, 1956). It has the disadvantage in this symposium of not distinguishing between atherosclerosis of the coronary trunks and its resultant myocardial ischaemia and infarction and the ischaemia and infarction which, in the Bantu, much more commonly results from syphilitic aortitis with occlusion of the coronary ostia.
Partly for this reason the term coronary hear disease is used in the symposium in the sense of atherosclerotic ischaemic heart disease.

Failure to distinguish between atherosclerosis. (the pathological lesion) on the one hand and its: clinical manifestations on the other, has led to $0^{+}$ much confusion of thought on the subject of coronary heart disease. The World Health Orga nization Study Group (1958) has defined athero $\frac{\pi}{\sigma}$ sclerosis as a "variable combination of changes of the intima of arteries (as distinguished froms arterioles) consisting of the focal accumulation of lipids, complex carbohydrates, blood and blood products, fibrous tissue and calcium deposits, andw associated with medial changes. It is to be dis $=\frac{\text { s }}{8}$ tinguished from the arteriolar changes of hyper $\frac{0}{3}$ tension, diffuse intimal thickening, Monckeberg's. sclerosis, and infections and 'allergic arteriats changes.' It may give rise to partial or completef occlusion of the affected vessel as a result of three mechanisms operating separately or together, viz N atheroma (with or without ulceration); throm- $-\circ$ bosis; subintimal haemorrhage (the latter is rela-? tively rare). We must stress that atherosclerosis $\vec{\square}$ is a focal lesion, and its severity may vary not onlyo from one vascular territory to another (coronary, aortic, cerebral, renal, peripheral) but also gic branches of the same vascular tree (e.g. left a d.0 right coronary arteries).

A number of clinical syndromes may result frown the effects of coronary atherosclerosis on the myocardium. These include:

(i) Angina pectoris;

(ii) coronary insufficiency;

(iii) cardiac infarction (major or minor);

(iv) cardiac failure;

(v) arrhythmia or heart block;

(vi) sudden death

These syndromes may occur separately or together in any combination and (with the excep-; tion of 'sudden death') in any order. There is 3 . only a rough correlation between the degree of $\delta$ coronary atherosclerosis and the severity of the clinical manifestations. In the presence ofo atherosclerosis, the development of clinical syn- $\rightarrow$ dromes depends on three factors.

I. The adequacy of the collateral circulation, which is the most important factor. If the collateral o circulation is poor, a single, sudden oclusion 0 may produce a severe clinical syndrome; in N the presence of a good collateral circulation, there may be multiple occlusions with littleo or no clinical manifestation.

2. The functional demands of the myocardium: where this is great (e.g. left ventricular hyper- 0 trophy, thyrotoxicosis) there may be severe $\bar{O}$ clinical manifestations with only slight atherosclerosis. 
3. The cardiac output: a poor cardiac output (e.g. in shock, paroxysmal tachycardia) may severely impair the coronary circulation, even if atherosclerosis is slight.

\section{The Clinical Picture of Ischaemic Heart Disease in African Populations}

Physicians in Southern Africa are all agreed that the clinical manifestations of coronary atherosclerosis are rarely seen in African populations. The clinical diagnosis of a case usually warrants publication in the local medical press, and Trowell of Uganda and Gelfand of Southern Rhodesia, both of whom have had a very considerable experience of medical practice in Africa, have only recently recorded their first probable cases of ischaemic heart disease in the African (Trowell and Singh, 1956; Gelfand and Kaplan, 1958). Elliott (1953) has summarized the experience of some of the large Bantu hospitals of Johannesburg, and has also found atherosclerotic coronary heart disease to be extremely uncommon. In Cape Town myocardial infarction is very rare in the Bantu. Schrire and Uys (1958) have published three cases of proven myocardial infarction collected at our hospital in a six-year period. Only one of these had coronary atheroma; he had been urbanised for 20 years.

The failure to diagnose coronary heart disease cannot be due to a different clinical presentation of the disease in this race. Admittedly the bedside diagnosis of ischaemic heart disease is largely dependent on a careful assessment of the patient's symptoms; in the Bantu, language difficulties prevent adequate history taking, and this might account for occasional cases of ischaemic heart disease being missed. Hunter (1946), has claimed that although cardiac infarction is common in the American Negro, the patients complain only of dyspnoea and not of pain, and hence the condition is infrequently diagnosed. In our experience, however, Bantu patients with syphilitic aortitis frequently present the typical symptoms of myocardial ischaemia and these do not differ in quality from the symptoms of atherosclerotic ischaemic heart disease in other races.

Electrocardiographic studies have confirmed this very low incidence of clinical ischaemic heart disease. Thus, Vogelpoel and Schrire (1955), at our hospital analysed $55^{\circ}$ consecutive electrocardiographs showing the 'classical' cardiac infarction pattern; the racial incidence per 100 electrocardiographs was: Whites 81.5; Cape Coloured 18.1; Bantu 0.4.

Electrocardiographic studies in the Bantu have their own peculiar features. The normal variants were reviewed by Brink (1956) on 50 healthy adult male and 50 healthy adult female Bantu subjects.
He concluded, inter alia, that 'the ST segment frequently showed coved forms in the precordial leads, but only in association with negative $T$ deflections. Raised ST segments are very common in the precordial leads and are not normally depressed below the isoelectric line.' Littmann (I946) had reported from a study of 300 healthy Negro adults among U.S. Army personnel that 'diphasic or inverted $T$ waves in the precordial leads were observed in I4 Negroes,' and concluded that this ' constituted a persistence of the juvenile pattern and was not a manifestation of organic heart disease.' Since Brink's report, most South African cardiologists are agreed that there is persistence of a 'juvenile pattern' in upwards of 5 per cent. of healthy adult Bantu subjects. Other abnormalities, especially of the ST segment: and $T$ wave of the right praecordial leads, are often recorded, but these are not believed to represent ischaemic heart disease. Many are probably due to what is grouped in this Medical School as ' myocardopathy of uncertain origin' (Bedford and Konstam, 1946; Gillanders, 1951 ; Higginson. et al., 1952; Becker et al., 1953; Davies et al., 1955).

The subject is discussed in great detail by Schrire and Gant (1958) in dealing with the differential diagnosis of beri-beri heart disease.

\section{The Pathology of Ischaemic Heart Disease in Africa}

Donnison (1929) was among the first to draw attention to the rarity of arteriosclerosis in the African races, but he was under the impression, certainly erroneous to-day, that hypertension was rare. Since then, pathologists from many parts of Africa have reported their experience, and data are available from Kenya (Vint, 1937), Uganda (Davis, I948), Northern Rhodesia (Hannah, I958) and Johannesburg (Becker, 1946; Higginson and Pepler, 1954). It is not always easy to compare the findings of these workers; different standards for grading severity have been used and a clear distinction between atherosclerosis of the coronary arteries, of the aorta and of other vascular territories has not always been made; nor has allowance always been made for the modifying effects of syphilis and hypertension, both of which are common in the Bantu. Nevertheless, all the above pathologists are unanimous that in their areas, marked coronary atherosclerosis is rare in the Bantu and African Negro and occlusive lesions with cardiac infarction are extremely rare.

The account by Hannah (1958) of his experiences in Northern Rhodesia is of special interest. His material is limited, but his study is one of few in which a comparison of White and Bantu necropsy findings. were made by the same 
pathologist. Thus in 42 Bantu dying a sudden death there were only 3 cases of moderate or severe coronary atheroma, and in only one of these was it the cause of death. In 22 Whites of comparable age who died suddenly, I 4 had moderate or severe coronary atheroma, and this was the immediate cause of death in six cases. Hannah (1958) commented that 'it was interesting to compare the stretchable grey intima of these African (coronary) vessels with the unyielding ochrous intima of specimens from like-aged Europeans.' From Ghana, Edington (1954) has reported a pattern of atherosclerosis in the West African Negro which is similar to that of the Bantu.

Apart from the difference in the degree of coronary atherosclerosis, the pathological picture of ischaemic heart disease in the Bantu differs in other respects as well. Thus ventricular aneurysm in the White race is usually associated with severe atherosclerosis; in the Bantu, however, ventricular aneurysms are associated with syphilis, tuberculosis, mycotic abscesses, etc., but never with marked atherosclerosis (Elliott, r953). Similarly coronary occlusion is the common cause of sudden death in the European, but only very seldom in the Bantu. Thus, Elliott (1953) in Johannesburg found 42 cases of sudden death in the European, in all of whom there was cardiac infarction; during the same period there were 40 sudden deaths in the Bantu, all of which were attributed to cardiovascular syphilis, none being due to coronary thrombosis with myocardial infarction.

Finally, it should be noted that cerebro-vascular accidents are quite common in the Bantu. Many of these are associated with hypertension, which is at least as common as in the Whites (Ordman, 1948), or with syphilis which is still prevalent among the Bantu. There is no adequate data from which to assess the incidence in the Bantu of cerebro-vascular accidents due to atherosclerosis per se. The dissociation between the low incidence of ischaemic heart disease and the comparatively greater incidence of hypertension with its attendant arteriosclerosis (cerebral and renal) was clearly stated by Brock and BronteStewart (1955). This dissociation is important since Laurie and Woods (1958a) have found it necessary to criticise certain editorial statements in South Africa on 'the Bantu's relative freedom from atherosclerosis.' Such loose statements deserve criticism. But Laurie and Woods have been misquoted by McMichael (1958) as stating 'there is as much atheroma in the Bantu as in Barts'; their comparison applied solely to ' cerebral vascular disease.' They (1958b) later reported that among a group of 150 Bantu hearts examined by perfusion 43 (69 per cent.) out of 63 diseased hearts had chronic ischaemic heart disease. No criteria are given for ischaemic heart disease. Still later (1958c) they foreshadow a paper reporting their "finding that the Bantu do commonly suffer from coronary heart disease.' This paper will be awaited with incredulity. Their criteria for distinguishing coronary heart disease from ' myocardopathy of uncertain origin' will be critically scrutinised!

We may sum up this section by stating that the pathology of coronary atherosclerosis in the Bantu is characterised by a low incidence of severe lesions, and that this is accompanied by an extremely low incidence of the clinical manifestations of ischaemic heart disease. It remains now to consider the factors which are responsible for this peculiar pattern.

Predisposing Factors in the Development of Ischaemic Heart Disease: Their Significance in African Populations

I. Age. The prevalence of ischaemic heart disease, and the severity of coronary atherosclerosis in White populations increases with age (White, 1947; White et al., 1950). The expectation of life of the average African is probably less than that of the Whites, and this is to some extent responsible for the lower total prevalence of ischaemic heart disease in the former. It can only be regarded as a minor factor, however, because in most of the studies described above, the inter-racial disparity was as striking in the younger age-groups as in the older. Thus, in the pathological survey in Johannesburg (Higginson and Pepler, 1954), the incidence of Grade 3 (i.e. severe) coronary and aortic atherosclerosis in Bantu men of the fourth decade was only 3 per cent., as against 32 per cent. in a comparable Danish series. Moreover, as Walker and Simson (1958) have pointed out, despite the lower average expectancy of life, many Bantu live to a ripe old age; nevertheless a Bantu death from ischaemic heart disease is a rare occurrence.

2. Genetic. In all comparative inter-racial studies of disease, the differentiation of environmental and genetic factors is a major problem. In considering the aetiology of ischaemic heart disease, this problem frequently recurs, e.g. when dealing with the role of hypertension, 'feminisation,' blood lipid pattern, etc. Studies on blood groups, haemoglobins, etc., have demonstrated genetic differences between African and White, and amongst African populations themselves (Dart, I95 I ; Singer, 1953), but the importance of these in relation to ischaemic heart disease has yet to be established.

A possible genetic factor has been invoked by Brink (1949) to account for the low incidence of cardiac infarction in the Bantu. He examined the hearts of $1_{5}$ Bantu and 17 White subjects by the 
injection technique of Schlesinger (1938) and found that while most of the Bantu had a 'third primary division' of their left coronary artery, this pattern was rarely found in the Whites. This extra branch in the Bantu supplied the territory between the anterior descending and the circumflex branches of the left coronary artery, i.e. it was strategically situated to maintain the myocardial blood supply in the event of an occlusion of one of the other primary divisions of the left coronary artery. Hence, Brink postulated that because of their potentially better coronary collateral circulation, the Bantu are less prone to cardiac infarction than the Whites. However, a more recent investigation by Singer (1958) in which a larger series of hearts was studied by dissection rather than by injection, showed no difference between the coronary artery pattern of the Bantu and the Whites.

It is possible that the characteristic 'juvenile pattern' of the Bantu electrocardiogram may represent a genetic trait, and the frequent recognition of a similar pattern in the healthy adult American Negro lends support to this suggestion (Littman, 1946; Wasserburger, 1955); but apart from indicating a possible inherent difference between the heart of the White and the Bantu, this has no direct bearing on the problem of atherogenesis.

3. Hormonal. In the White races, coronary atherosclerosis is more severe in the male than in the female during the reproductive years of their lives. After the menopause, the severity of the lesion in the female increases, and begins to approach that of age-matched males (Ackerman $e t$ al., 1950). This suggests that 'femininity' protects against the development of atherosclerosis, and in some experimental animals the administration of oestrogens protects against the development of cholesterol-induced coronary atherosclerosis (Pick et al., 1952). Late development of a beard, poorly developed body hair and gynaecomastia are not uncommon in Bantu men without overt liver disease, and it has been suggested that the low incidence of ischaemic heart disease may be a manifestation of 'feminity.' Hair growth pattern, however, is not solely related to gonadal activity; it certainly has a genetic basis. Recently Bersohn and Oelofse (1957) have studied this problem from the biochemical point of view and compared the urinary excretion of oestrogens in a series of clinically normal Bantu and White men. They were able to demonstrate a substantially greater excretion of oestrogen by the Bantu, most of which was accounted for by an increase in the oestradiol fraction. Their findings, therefore, are consistent with the 'feminisation' hypothesis, and this may play some part in determining the immunity of the Bantu to coronary heart disease. Gillman et al. (1957) have drawn attention to the importance of other endocrine glands in the producti on of atherosis of the aorta in the baboon, even on diets low in animal fat and containing no cholesterol. There can be little doubt about the importance of endocrine controlled metabolic factors, but the application of these experimental observations to the problem of inter-racial differences in man is still obscure.

4. Climate. The prevalence of ischaemic heart disease in the White races in Africa is comparable to that of White races in the rest of the world. White men have been living in this part of the African continent for three centuries under the same climatic conditions as the indigenous races; the incidence of ischaemic heart disease in them is increasing from year to year (Brock and Gordon, 1957), while in the Bantu it is still extremely low. Clearly then, climate cannot be regarded as playing a significant role in protecting the Bantu from this disease.

5. Physical Activity. The suggestion that increased physical activity may inhibit the development of ischaemic heart disease stemmed from the epidemiological observation in Great Britain of a much lower incidence of ischaemic heart disease in semi-skilled and unskilled labourers than amongst those in sedentary occupations (Registrar-General 1951). Further support for this suggestion came from the study by Morris et al. (1953), who showed that London bus drivers were more susceptible to ischaemic heart disease than the more active bus conductors. They (1956) drew attention to the larger size of drivers which might indicate a genetic factor, but Morris et al. (1958) have recently re-stated the hypothesis that "physical activity of work is a protection against coronary (ischaemic) heart disease.' Exercise might operate through the mechanism of encouragement of coronary anastomoses (Eckstein, 1957) or through an effect on intravascular clotting.

The great majority of the Bantu, both in the towns and in their own reserves, are engaged in strenuous physical activity at work; in view of the above contradictory observations, however, it is not possible to assess the role of this activity in protecting the Bantu from ischaemic heart disease.

6. Emotional Stress. The difficulties involved in the quantitative assessment of human emotions are well known (Arnott, 1954; Sprague, 1958). Hence, it is not surprising to find that when attempts have been made to establish the relationship of emotional stress to the development of ischaemic heart disease, the results have been conflicting, e.g. Miles and his associates (1954) studied 46 young men with ischaemic heart disease 
and concluded that ' we simply do not have evidence, however, that anxiety or other emotional stress is related to the genesis of the atherosclerosis.' Angina pectoris is undoubtedly precipitated by anger and fear, and there is a clinical impression that episodes of occlusion may follow periods of acute psychological stress. The precipitating mechanism here may possibly involve the mechanisms of intravascular thrombosis.

The equable temperament of the Bantu is often quoted with approval and is widely regarded as an important reason for his immunity to ischaemic heart disease. We would stress, however, that as far as exposure to psychic trauma is concerned, the difference between the Bantu and the White races is qualitative rather than quantitative. What the Bantu avoids in the way of ambitious drives and the stress of professional responsibility, he makes up in his superstitious fear of elemental forces, tribal taboos, witchcraft, and in the conflicts which arise when he comes in contact with White civilisation. But in the absence of any definite evidence about the role of emotions in the causation of ischaemic heart disease in general, it is futile to speculate about its effects in the Bantu specifically.

7. Disease. Chronic wasting diseases are said to protect against the development of ischaemic heart disease in the White races (Wilens, 1947). Such diseases, particularly chronic infections, chronic liver disease and malnutrition are more common among the Bantu than among the Whites, and it might be possible that this in some unknown way is associated with the decreased severity of atherosclerosis, and in lowering the incidence of clinical ischaemic heart disease. Nevertheless, even among the perfectly fit Bantu, severe atherosclerosis and ischaemic heart disease is very rare, and this must depend on factors other than chronic disease.

Conversely, certain diseases which are said to be associated with ischaemic heart disease are relatively rare in the Bantu. These include diabetes mellitus (Gelfand, 1957), cholelithiasis (Lopis, 1947) and peptic ulcer.

8. Diet. Several surveys have been made of the dietetic habits of the South African Bantu (Walker and Arvidsson, 1954; Bronte-Steward et al., I955), and in all these, similar patterns of food consumption have been found (Figs. 2 and 3 ). The Bantu diet is comparable to that of the White with respect to total caloric consumption, but there the resemblance ends. His staple food is maize, with some addition of sorghum, beans, and pumpkin. These are supplemented on special occasions by meat feasts, and in some tribes, soured milk is popular. The maize meal is consumed either as a simple porridge, or it may be baked into dry biscuits, or it may be allowed to ferment to produce a sour porridge, or it may be used as the basis for a fermented beverage. It will be seen, therefore, that the Bantu diet is deficient by comparison with Western standards in animal protein (although the total protein content may be fairly high); it has a very low total fat content, but it is rich in carbohydrate and food fibre. A recent survey in which the diets of rural Bantu were compared with White professional and clerical men in Cape Town showed that the former derived 18 per cent. of their calories from fat as compared with 43 per cent. by the latter (Merskey et al., 1958).

Of all these dietary variables, that which has received most attention in relation to ischaemic heart disease is the dietary fat. The low total fat consumption of the Bantu is comparable to that of the Japanese, Chinese, Guatemalans, Southern Italians and Yemenite Jews, amongst all of whom ischaemic heart disease is similarly uncommon. Much of the Bantu fat intake is derived from maize, i.e. it has a high content of unsaturated fatty acids; the little saturated fat which he gets is from soured milk and the rare meat feasts. This relatively high unsaturated fat consumption may also be compared with that of the Japanese (fish), Chinese (soya bean oil), Southern Italians (olive oil) and the Yemenite Jews (sesame oil) Conversely, the fat consumption of the Bantis. is in sharp contrast with that of the privileged White races; the latter is characterised by a high content of saturated fats, both from animal sources and from artificially saturated (hydrogenated) vegetable oils, and consequently by a relatively low content of unsaturated fats.

This qualitative and quantitative difference in fat consumption is the most clearly delineated exogenous factor which may account for the relative immunity of the Bantu to ischaemic heart disease. Walker and Bersohn (1957) have stressed the importance of the whole Bantu dietary pattern, but the specific effects of the high crude fibre and low animal protein intake have yet to be established.

Exciting Factors in the Development of Ischaemic Heart Disease: Their Significance in African Populations

Serum Cholesterol Level

A great body of epidemiological, biochemical, clinical and experimental evidence has been assembled which testifies to a close association between the serum cholesterol level and the development of ischaemic heart disease. (This evidence is reviewed elsewhere in this journal by Bronte-Stewart.) In general, high serum-cholesterol levels amongst population groups are associated with a high prevalence of the disease, while 


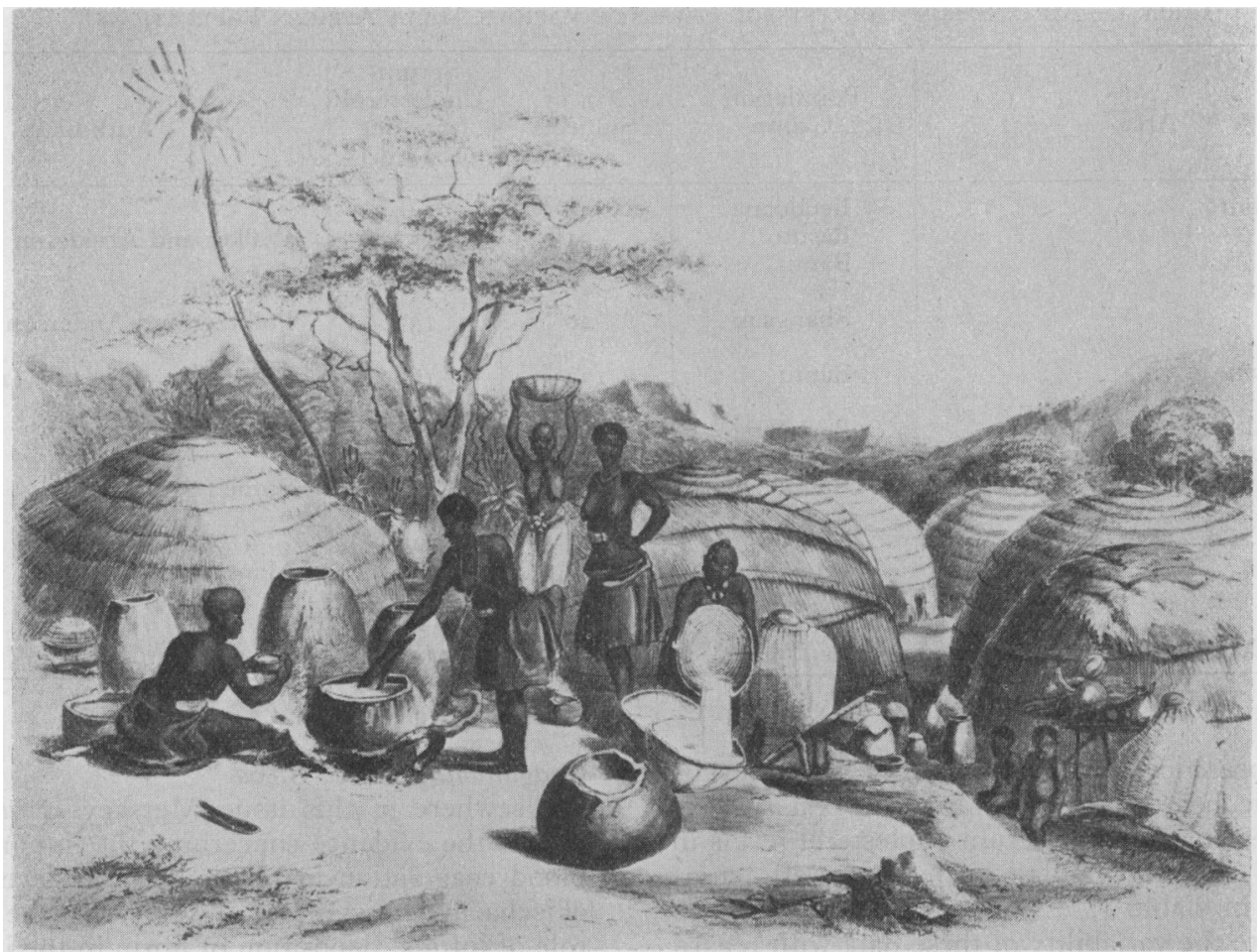

Figs. 2 and 3.-From 'The Kafirs Illustrated,' by G. F. Angus, Hogarth, London, I 849 . These two pictures typify the primitive life of the Bantu, showing beehive huts, a cattle kraal, maize meal and earthen pots.

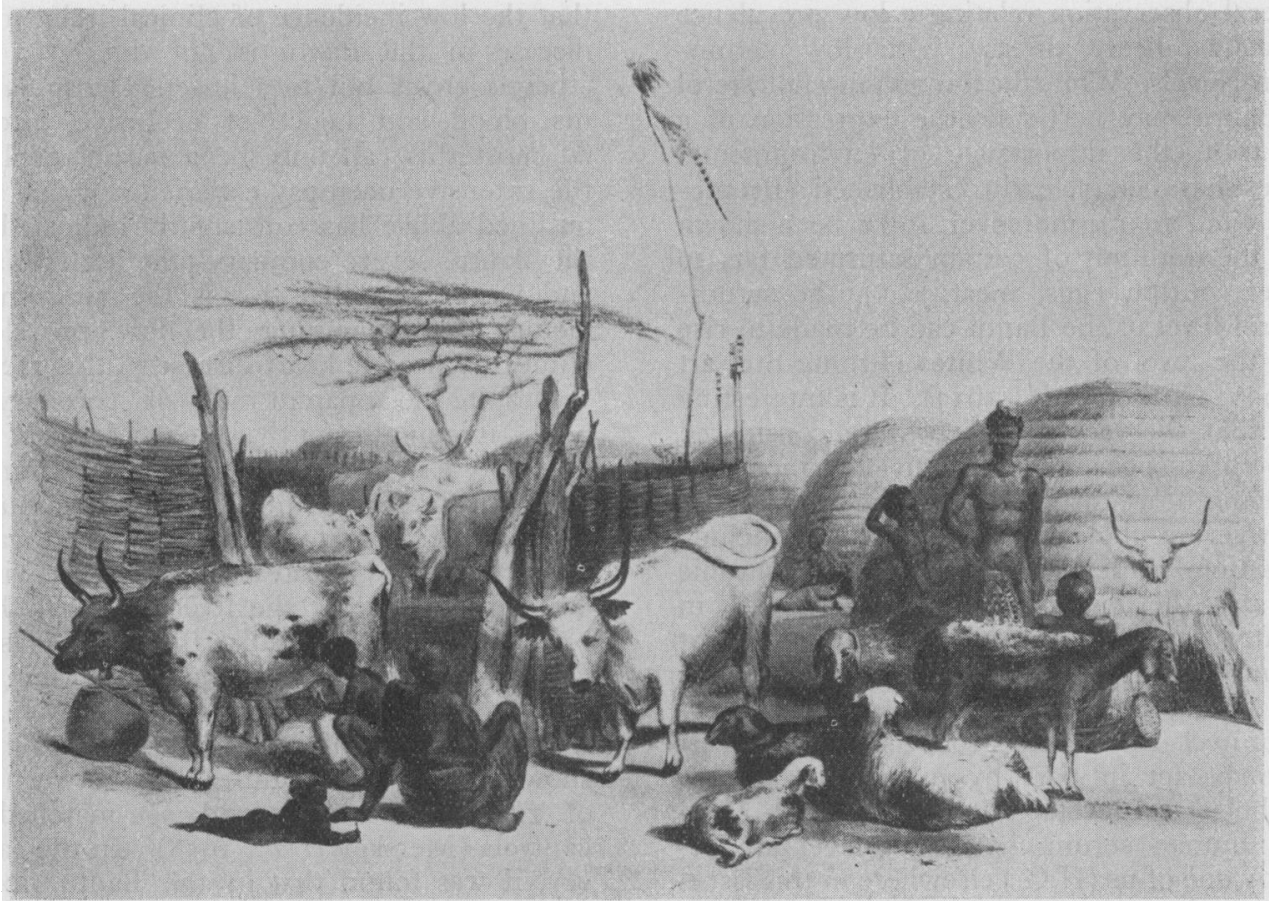


Table I.-Mean Serum-Cholesterol Levels of Various Adult African Populations

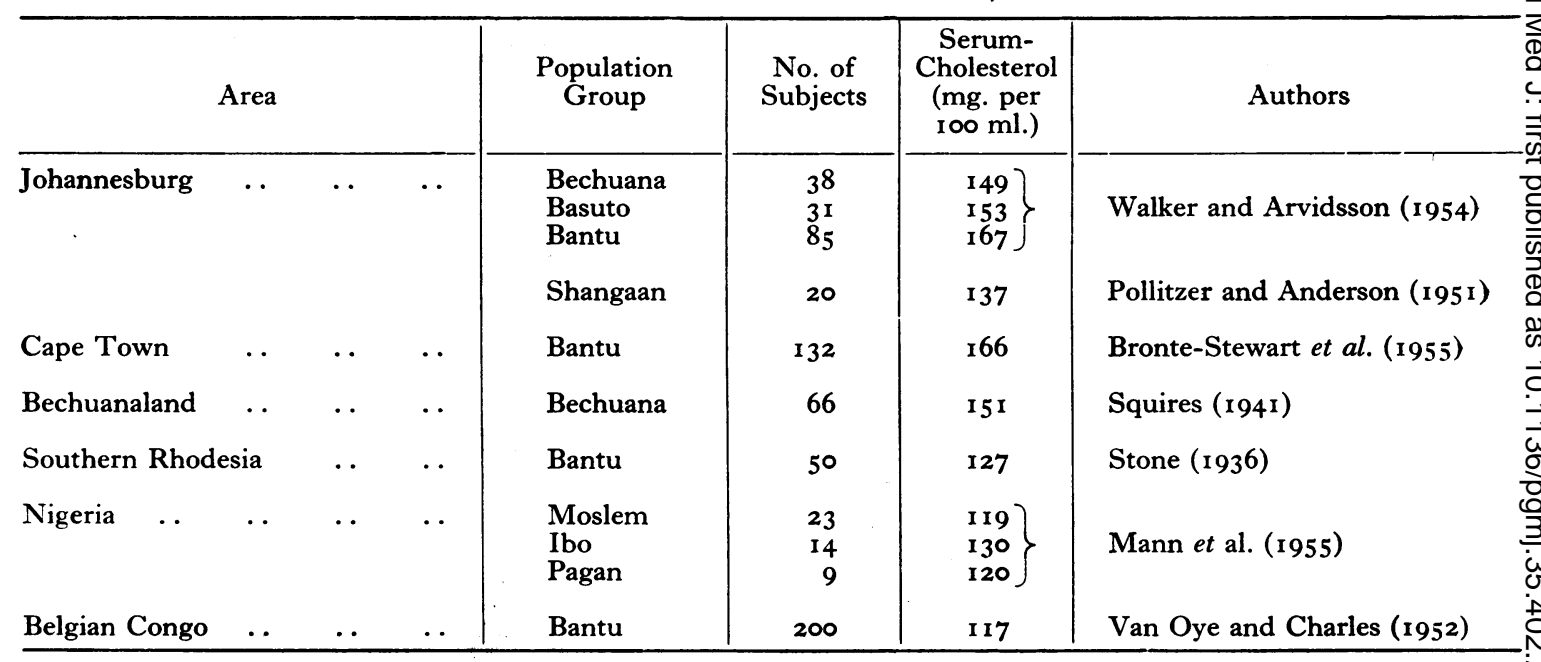

in the presence of low-serum-cholesterol levels, ischaemic heart disease is rare. Several surveys have been made of the serum-cholesterol levels in various African populations. These are summarised in Table $\mathrm{I}$.

Despite the variability of these data with regard to the age and sex of the subjects and the differences in the analytical techniques, the consistently low serum-cholesterol levels of these populations are clearly indicated. This is in keeping with the general observation relating a low prevalence of ischaemic heart disease with low serumcholesterol levels. While the low serum-cholesterol of the Bantu may partly be the expression of a genetic trait, the importance of environmental influences has been clearly established (BronteStewart et al., 1955); moreover, it has been shown that by the addition of certain saturated fats to their diet (butter, eggs, meat, etc.), the serumcholesterol level of the Bantu can be made to rise towards the level of the Whites (Bronte-Stewart et al., 1956; Gordon et al., 1957). It is interesting to note that the factors which were considered above to " predispose' the Bantu to a low incidence of ischaemic heart disease are all thought to produce low serum-cholesterol levels. These include ' feminisation,' increased physical activity, chronic disease and the low-fat diet relatively rich in unsaturated fatty acids. It is possible also that the serum-cholesterol level is partly under genetic control, and it may be that the genetic factors which protect the Bantu from ischaemic heart disease may act in part by maintaining a low serum-cholesterol level. The factors which regulate the human serum-cholesterol level are reviewed by one of us (H.G.) elsewhere in this issue.

\section{Coagulability of the Blood}

Elsewhere in this issue Merskey et al. (1958) $\vec{\longrightarrow}$ review the evidence concerning the importance ofo blood coagulation in relation to the development of ischaemic heart disease. Apart from the possibje 0 role of intimal deposition of fibrin in the initiation. of atheromatous lesions, thrombosis in athere 8 sclerotic arteries is an important cause of coronaty occlusion, and hence of the clinical manifestations $\frac{}{-}$ of ischaemic heart disease. It has been suggested that the low incidence of clinical ischaemic heart $\mathbb{Q}$ disease in the Bantu is not due to a lack of $\overrightarrow{\vec{F}}$ atherosclerosis but to a lessened coagulability of $\frac{0}{3}$ his blood and hence of occlusive thrombosis. At most this can only be a partial explanation; the extensive necropsy experience which we have outlined above has consistently indicated that in 3 the Bantu, severe coronary atherosclerosis is rareand we believe that this is the most important 3 . factor in determining the low prevalence of clinical ischaemic heart disease in this race.

Despite the apparent rarity of " coronary throm-을 bosis,' it is significant that the incidence of cerebral thrombosis in the Bantu differs little from that in the Whites. It is of interest also that a number of diseases peculiar to under-privileged races are $\%$ characterised by intravascular clotting, viz. veno- $N$ occlusive disease of the liver; tropical thrombophlebitis; and endocardial thrombosis associatedo with myocardopathy of uncertain origin (Brock I955).

In vitro tests of blood coagulability have not $\stackrel{5}{+}$ shown any significant differences between a group 0 of rural Bantu men and age-matched Whiteo controls (Merskey et al., 1958). In the same survey, it was found that in the Bantu fibrinolytico 
activity as measured by the clot lysis time was characteristically faster than in the White controls and this may play some part in depressing the thrombotic phase (Duguid, 1955) of atherogenesis in the Bantu. A possible connection between this mechanism and the Bantu diet pattern is suggested by the as yet unconfirmed work of Greig (1956), who showed that when saturated dietary fats were eaten, fibrinolysis was inhibited, but when unsaturated fats (maize oil and arachis oil) were eaten fibrinolytic activity was not affected.

\section{Conclusions}

A number of endogenous and exogenous factors may collectively be responsible for the low prevalence of ischaemic heart disease in African populations. While the importance of genetic pattern is not belittled, we believe that environmental influences are the more important determinants of this low prevalence; of these, the role of diet is the most clearly established and the most susceptible to natural and experimental change.

The indigenous races have derived many benefits from the spread of 'Western' civilization through the African continent, and it is expected that they will continue to do so. The price which they will pay for these benefits may include a loss of the favourable environment which protects them from ischaemic heart disease. The history of the West African Negroes who migrated to the United States of America illustrates this potential danger: thus, in the Southern States, where their average standard of living is comparatively low, the Negroes have retained some of their freedom from ischaemic heart disease (Thomas et al., 1957); further north, where the mode of living of the Negro more closely approaches that of the White, the prevalence of coronary heart disease in the two races is equally high (Stamler, 1956). Time alone will tell whether a similar fate is in store for the indigenous African races.

\section{Summary}

I. There is a striking freedom among the Bantu and Negro populations of Africa from ischaemic heart disease. This freedom is evident from clinical, electrocardiographic and pathological evidence. It is real and not attributable to lesser age expectation.

2. On the other hand, the experience of these peoples in respect of hypertension and cerebrovascular accidents is not so favourable.

3. Evidence on the distribution and severity of atherosclerosis in the same peoples is conflicting; in the aorta and coronary arteries it is usually less severe and extensive than in Europeans.

4. The African Bantu have mean serumcholesterol levels much lower than Europeans of the same age and sex. There is a tendency for the mean level to rise with urbanisation. In individual Bantu subjects the serum-cholesterol levels can be raised by adding certain 'saturated' fats to the diet. This cholesterol raising effect can be neutralised by substituting or adding certain ' unsaturated' oils. No other dietary manipulations have a comparable effect.

5. Certain factors are reviewed which might explain the Bantu freedom from ischaemic heart disease. Apart from the effects of diet and of the serum-cholesterol levels the reasons remain obscure.

\section{BIBLIOGRAPHY}

ACKERMAN, R. F., DRY, T. J., and EDWARDS, J. E. (1950), Circulation, $\mathrm{I}, \mathrm{I} 345$.

ARNOTT, W. M. (1954), Lancet, i, $125 \mathrm{I}$.

BECKER, B. J. P. (1946), S. Afr. F. med. Sci., I1, 97.

BECKER, B. J. P., CHATGIDAKIS, C. B., and van LINGEN, B. (1953), Circulation, 7, 345 .

BEDFORD, D. E., and KONSTAM, G. L. S. (1946), Brit. Heart $\mathcal{Y}$., $8,236$.

BERSOHN, I., and OELOFSE, P. J. (1957), S. Afr. med. F., 31, 1172.

BRINK, A. J. (I949), Clin. Proc., 8, 137.

BRINK, A. J. (1956), S. Afr. F. Lab. clin. Med., 2, 97.

BROCK, J. F. (1949), S. Afr. med. F., 23, 1000.

BROCK, J. F. (1955), Nutr. Rev., 13, I.

BROCK, J. F., and BRONTE-STEWART, B. (1955), Minn. Med., 38, 852.

BROCK, J. F., and GORDON, H. (1957), S. Afr. med. F., 31, 663.

BRONTE-STEWART, B., ANTONIS, A., EALES, L., and BROCK, J. F. (I956), Lancet, i, 52 I.

BRONTE-STEWART, B., KEYS, A., and BROCK, J. F. (1955), Ibid., ii, 1 103.

DART, R. A. (I95I), 'African Serological Patterns and Human Migrations,' S. Afr. Archaeol. Soc., Cape Town.

DAVIES, J. N. P. (1948), E. Afr. med. F., $25,454$.

DAVIES, J. N. P., and BALL, J. D. (1955), Brit. Heart F., 17, 337.

DONNISON, C. P. (1929), Lancet, i, 6.

DUGUID, J. B. (1955), Brit. med. Bull., 11, 36.

ECKSTEIN, R. W. (I957), Circulation Research, 5, 230.

EDINGTON, G. M. (1954), Trans, roy. Soc. trop. Med. Hyg., 48, 419.

ELLIOTT, G. A. (1953), Leech, 23, 25.

GELFAND, M. (I957), 'The Sick African,' 3rd ed., Juta, Cape Town.

GELFAND, M., and KAPLAN, M. (1958), Cent. Afr. F. Med., 4, I 57.

GILLANDERS, A. D. (1951), Brit. Heart f., 13, 177.

GILLMAN, J., and GILBERT, C. (1957), Exp. Med. Surg., I5, 181. GORDON, H., LEWIS, B., EALES, L., and BROCK, J. F. (I957), Ibid., ii, I 299.

GREIG, H. B. W. (1956), Ibid., ii, I6.

GRUSIN, H. (1954), Circulation, 9, 860.

HAILEY, Lord (1957), 'An African Survey,' rev. ed., O.U.P., London.

HANNAH, J. B. (1958), Cent. Afr. F. Med., 4, r.

HIGGINSON, J., GILLANDERS, A. D., and MURRAY, J. F. (1952), Brit. Heart F., 14, 213.

HIGGINSON, J., and PEPLER, W. J. (1954), F. clin. Invest., 33, 1366 .

HUNTER, W. S. (1946), Ұ. Amer. med. Ass., 131, 2.

LAURIE, W., and WOODS, J. D. (1958a), Lancet, i, 231.

LAURIE, W., and WOODS, J. D. (1958b), Ibid., ii, 812.

LAURIE, W., and WOODS, J. D. (1958c), Ibid., ii, 1372.

LITTMAN, D. (1946), Amer. Heart F., 32, 370.

LOPIS, S. (1947), Clin. Proc., 6, 338.

McMICHAEL, J. (1958), Lancet, i, 528.

MANN, G. V., NICOL, B. M., and STARE, F. J. (1955), Brit. med. $尹$., ii, 1008 .

MERSKEY, C., GORDON, H., and LACKNER, H. (1958), S. Afr. med.' F., 32, 855 .

MILES, H. H. W., WALDFOGEL, S., BARRABEE, E. L., and COBB, S. (1954), Psychosom. Med., 16, 455. 
MORRIS, J. N., and CRAWFORD, M. D. (1958), Brit. med. F., ii, 14,85 .

MORRIS, J. N., HEADY, J. A., and RAFFLE, P. A. B. (1956), Lancet, ii, 569 .

MORRIS, J. N., HEADY, J. A., RAFFLE, P. A. B., ROBERTS, C. G., and PARKS, J. W. (I953), Ibid., ii, I053 and IIII.

ORDMAN, B. (1948), Clin. Proc., $7,183$.

PICK, R., STAMLER, J., ROBARD, S., and KATZ, L. N. (1952), Circulation, 6, 858.

POLITZER, W. M., and ANDERSON, I. (1957), S. Afr. f. med. Sci., 22, 23.

REGISTRAR-GENERAL, Decennial Supplement, England and Wales (1951), 'Occupational Mortality,' part I, p. I3, H.M.S.O., London.

SCHLESINGER, M. J. (1938), Amer. Heart F., 15, 528.

SCHRIRE, V., and GANT, J. (1958), in press.

SCHRIRE, V., and UYS, C. J. (1958), in press.

SELIGMAN, C. G. (1957), ' Races of Africa,' Oxford University Press, London.

SINGER, R. (1953), Amer. Anthrop., 55, 634.

SINGER, R. (1958), Amer. F. Anat., in press.

SPRAGUE, H. B. (1958), Circulation, $17, \mathrm{I}$.

SQUIRES, B. T. (1941), S. Afr. F. med. Sci., 6, 53.

STAMLER, J. (1956), Neb. St. med. F., 41, 75.

STONE, W. (1936), Trans. roy. Soc. trop. Med. Hyg., 30, 165.
THOMAS, W. A., BLACHE, J. O., and LEE, K. T. (1957), Arch. intern. Med., 100, 423.

TROWELL, H. C., and SINGH, S. A. (r956), E. Afr. med. F.,

van OYE, E., and CHARLES, P. (1952), Ann. Soc. belge Méd. trop., 32, 297.

VINT, F. W. (1937), E. Afr. med. F., 13, 332.

VOGELPOEL, L., and SCHRIRE, V. (I955), Lancet, ii, 1 I08.

WALKER, A. R. P., and ARVIDSSON, U. V. (1954), F. clin. Invest., 33, 1358 .

WALKER, A. R. P., and BERSOHN, I. (1957), S. Afr. med. F., suppl.' Medicine in South Africa,' p. 106.

WALKER, A. R. P., and SIMSON, I. W. (1958), Lancet, i, I I 26.

WASSERBURGER, R. H. (1955), Amer. F. Med., 18, 428.

WHITE, P. D. (1947), ' Heart Disease,' 3rd ed., MacMillan, New York.

WHITE, N. K., EDWARDS, J. E., and DRY, T. J. (1950), Circulation, $\mathrm{I}, 645$.

WILENS, S. L. (1947), Arch. intern. Med., 79, 29.

WOOD, P. (1956), 'Diseases of the Heart and Circulation,' 2nd ed., Eyre and Spottiswoode, London.

WORLD HEALTH ORGANISATION (1957), Techn. Rep. Ser., No. II 7 .

WORLD HEALTH ORGANISATION (I958), Techn. Rep. Ser., No. 143 .
This symposium was contributed on invitation of the editor, by the staff of the Department of Medicine, University of Cape Town, South Africa.

The original work on which many of the views are based was carried out with the financial support of many organizations, to which grateful acknowledgment is made. The Council for Scientific and Industrial Research supports the Clinical Nutrition Research Unit in the Department and has supported other parts of the studies ad hoc. Acknowledgment is also made to the National Heart Institute, Public Health Service, United States of America; the Cape Town City Council; th 8 South African Mutual Life Assurance Societ of Cape Town; Irwin and Johnson Ltd., \& Cape Town; the South African Fish Oil Producers' Association (Pty.) Ltd., of Cape Town; the A. R. Richardson Research Fund and the Senate Research Fund of the University of Cape Town.

Bibliography continued from page 202-B. Bronte-Stewart, M.D., M.R.C.P.

BRONTE-STEWART, B., and BLACKBURN, H. (1958), 'Essential Fatty Acids' (Proceedings of the Fourth International Conference held at the University of Oxford in July, 1957, on the Biochemical Problems of Lipids, p. 180, Butterworths Scientific Publications, London).

CHERNICK, S., SRERE, P. A., and CHAIKOV, I. L. (1949), F. biol. Chem., 179, 113 .

DAWBER, T. R., MOORE, F. E., and MANN, G. V. (1957), Amer.' F. publ.' Hlth., 47, No. 4, part 2, p. 4.

de WOLFE, M. S., and WHYTE, H. M. (1958), Aust. Ann. Med., $7,47$.

GERTLER, M. M., and WHITE, P. D. (1954), ' Coronary Heart Disease in Young Adults: A Multidisciplinary Study' p. 103, Commonwealth Fund, Cambridge (Mass.), Harvard Ưniversity Press.

GOFMAN, J. W., GLAZIER, F., TAMPLIN, A., STRISOWER, B., and DE LALLA, O. (1954), Phys. Rev., 34, 589.

GSELL, O. (1948), In: Hottinger, A., Gsell, O., Uuehlinger, E. Salzmann, C., and Labhart, A., 'Hungerkrankheit, Hungerodem und Hungertuberkulose,' p. 16r, Schwabe, Basel.

KEYS, A., KIMURA, N., KUSUKAWA, A., BRONTESTEWART, B., LARSEN, N., and KEYS, M. H. (1958), Ann. intern. Med., 48, 83

LAWRY, E. Y., MANN, G. V., PETERSON, A., WYSOCKI, A. P., O'COONNELL, R., and STARE, F. J. (1957), Amer. '尹.
Med., 22, 605.
LEWIS, B. (1958), Lancet, ii, $7 \mathrm{r}$.

LOBER, P. H. (1953), Arch. Path., 55, 357.

MERSKEY, C., and LACKNER, H. (1959), Postgrad. med. f., 윽 35, 203 .

MITCHELL, J. R. A., and BRONTE-STEWART, B. (1959), $\frac{D}{O}$

Lancet, in press.

MORETON, J. R. (1950), f. Lab. clin. Med., 35, 373.

MORRIS, J. N. (195I), Lancet, i, 69.

OLIVER, M. F. (1958), Practitioner, 180, 202.

OLIVER, M. F., and BOYD, G. S. (1953), Clin. Sci., 12, 293.

OLIVER, M. F., and BOYD, G. S. (1955), Brit. Heart f., 17, 299. స్

PAGE, I. H. (1954), Circulation, ro, I.

PATERSON, J. C., and DERRICK, J. B. D. (1957), Ibid., 16, 512 POMERANZE, J., BEINFIELD, W. H., and CHESSIN, M. (1954), Ibid., I0, 742.

RUTSTEIN, D. D., INGENITO, E. F., CRAIG, J. M., and MARTINELLI, M. (1958), Lancet, i, 545 .

SCHETTLER, G. (1950), Klin. Wschr., 28, 565.

SMITH, E. B. (1957), Lancet, ii, 9ro.

WEINHOUSE, S., and HIRSCH, E. F. (1940), Arch. Path., 29, 31.

YATER, W. M., WELSH, P. P., STAPLETON, J. F., and CLARK, M. L. (1951), Ann. intern. Med., 34, 352. 